\title{
Conhecimento e comportamento de acadêmicos de enfermagem acerca da prevenção de infecções sexualmente transmissíveis
}

Nursing students' knowledge and behavior about prevention of sexually transmitted infections Conocimiento y comportamiento de los estudiantes de enfermería sobre la prevención de infecciones de transmisión sexual

\section{Caroline Clemente Merenhque ${ }^{\mathrm{I}}$, Camila Nunes Barreto ${ }^{\mathrm{II}}$, Luiza Cremonese ${ }^{\mathrm{III}}$, Graciela Dutra Sehnem ${ }^{\mathrm{IV}}$, Carolina Carbonell Demoriv ${ }^{\mathrm{v}}$, Eliane Tatsch Neves ${ }^{\mathrm{VI}}$}

\begin{abstract}
Resumo: Objetivo: descrever o conhecimento e comportamento de acadêmicos de enfermagem acerca das infecções sexualmente transmissíveis. Método: realizaram-se três sessões grupais no período de novembro de 2019, com a participação de acadêmicos de enfermagem. A análise das informações fundamentou-se na análise de conteúdo operativa. Resultados: os universitários demonstraram possuir conhecimento sobre as infecções sexualmente transmissíveis. Em relação à percepção de risco, sentem-se vulneráveis, embora tenham conhecimento quanto à proteção. O meio acadêmico proporciona maiores susceptibilidades, assim como as mídias sociais. Durante a graduação, ampliaram seus conhecimentos e passaram a ter mais cuidado, principalmente ao diagnosticar novas infecções de usuários do sistema de saúde atendidos em aula prática e estágio. Conclusão: a adoção de práticas seguras está associada ao conhecimento adquirido e a verificação de novos casos de usuários em cenários de aprendizagem. É essencial que as instituições de ensino, especialmente as universidades, desenvolvam ações educativas direcionadas aos discentes.
\end{abstract}

Descritores: Doenças sexualmente transmissíveis; Risco; Educação em saúde; Comportamento sexual; Enfermagem

Abstract: Objective: to describe nursing students' knowledge and behavior about sexually transmitted infections. Method: three group sessions were held in November 2019, with the participation of nursing students. The analysis

\footnotetext{
${ }^{\text {I }}$ Enfermeira. Graduada em Enfermagem pela Universidade Luterana do Brasil (ULBRA), campus Cachoeira do Sul. Cachoeira do Sul, RS, Brasil. E-mail: carolclemente@outlook.com Orcid: https://orcid.org/0000-0003-3008-8173

${ }^{\text {II }}$ Enfermeira. Doutoranda em Enfermagem pelo Programa de Pós-Graduação em Enfermagem (PPGEnf) da Universidade Federal de Santa Maria (UFSM). Docente no curso de Enfermagem da Universidade Luterana Do Brasil (ULBRA), campus Cachoeira do Sul. Cachoeira do Sul, RS, Brasil. E-mail: camilabarreto_6@msn.com Orcid: https://orcid.org/0000-0001-5638-550X

III Enfermeira. Doutoranda no PPGEnf/UfSM. Docente na ULBRA - Campus Cachoeira do Sul. Cachoeira do Sul, RS, Brasil. E-mail: lu_cremonese@hotmail.com Orcid: https://orcid.org/0000-0001-7169-1644

IV Enfermeira. Doutora pelo PPGEnf/UfRGS. Docente do Departamento de Enfermagem e Programa de Pós-Graduação em Enfermagem da Universidade Federal de Santa Maria, Santa Maria, RS, Brasil. E-mail: graci_dutra@yahoo.com.br Orcid: https://orcid.org/0000-0003-4536-824X

${ }^{\vee}$ Enfermeira. Doutora em Ciências da Saúde pela Universidade Federal de Pelotas. Chefe de Enfermagem Hospital Guarnição de Bagé, Bagé, RS, Brasil. E-mail: carolinacdemori@gmail.com Orcid: https://orcid.org/0000-0002-5153-549X

${ }^{\mathrm{V}}$ Enfermeira. Doutora em Enfermagem pela Escola de Enfermagem Anna Nery da UFRJ. Pós-doutorado em Enfermagem em Saúde Pública pela Escola de Enfermagem de Ribeirão Preto da USP. Docente do Departamento de Enfermagem e Programa de Pós-Graduação em Enfermagem da Universidade Federal de Santa Maria, Santa Maria, RS, Brasil. E-mail: eliane.neves@ufsm.br Orcid: https://orcid.org/0000-0002-1559-9533
} 
of the information was based on the analysis of operative content. Results: the university students demonstrated knowledge about sexually transmitted infections. Regarding risk perception, they feel vulnerable, although they are aware of protection. The academic environment provides greater susceptibilities, as well as social media. During graduation, they expanded their knowledge and began to be more careful, especially when diagnosing new infections of users of the health system met in practical class and internship. Conclusion: the adoption of safe practices is associated with acquired knowledge and the verification of new cases of users in learning scenarios. It is essential that educational institutions, especially universities, develop educational actions towards students.

Descriptors: Sexually transmitted diseases; Risk; Health education; Sexual behavior; Nursing

Resumen: Objetivo: describir el conocimiento y el comportamiento de los estudiantes de enfermería sobre las infecciones de transmisión sexual. Método: en noviembre de 2019 se celebraron tres sesiones grupales, con la participación de estudiantes de enfermería. El análisis de la información se basó en el análisis del contenido operativo. Resultados: los estudiantes universitarios demostraron conocimientos sobre infecciones de transmisión sexual. En cuanto a la percepción del riesgo, se sienten vulnerables, aunque son conscientes de la protección. El entorno académico proporciona mayores susceptibilidades, así como las redes sociales. Durante la graduación, ampliaron sus conocimientos y comenzaron a ser más cuidadosos, especialmente cuando se diagnostican nuevas infecciones de usuarios del sistema de salud que asistieron en clase práctica y pasantías. Conclusión: la adopción de prácticas seguras se asocia con los conocimientos adquiridos y la verificación de nuevos casos de usuarios en escenarios de aprendizaje. Es esencial que las instituciones educativas, especialmente las universidades, desarrollen acciones educativas dirigidas a los estudiantes.

Descriptores: Enfermedades de transmisión sexual; Riesgo; Educacion em salud; Comportamiento sexual; Enfermería

\section{Introdução}

As infecções sexualmente transmissíveis (IST) são transmitidas, principalmente, por meio do contato sexual sem o uso de preservativo com uma pessoa que esteja infectada. Ainda assim, há situações nas quais, mesmo com o uso do preservativo, pode ocorrer a transmissão, como nos casos em que há o rompimento da camisinha, ejaculação de sêmen na boca e contato em locais que o preservativo não cobre. Nesse caso, a pele e revestimentos da mucosa, vagina e reto são portas de entrada dos microrganismos (bactérias, vírus ou parasitas). Embora existam inúmeras estratégias para prevenção combinada desses agravos, como o uso de preservativo, realização de testagens rápidas, imunização (nos casos de vírus da imunodeficiência humana (HIV) e hepatite B), profilaxias pré e pós exposição ao HIV e outras IST, observa-se a persistência de casos novos em distintas faixas etárias e populações. ${ }^{1}$

Dentre os mais de trinta agentes patogênicos transmitidos pelas relações sexuais sem 
proteção, oito são causadores das principais demandas no âmbito da saúde devido à magnitude e extensão dos agravos ocasionados às populações. Das oito infecções, quatro são curáveis: sífilis, clamídia, tricomoníase e gonorreia. Embora não sejam curáveis, as outras quatro podem ser controladas e tratáveis com o uso de medicamentos e acompanhamento de saúde: vírus da imunodeficiência humana (HIV), hepatite B, herpes e papiloma vírus humano (HPV)..$^{2-3}$

As IST são predominantes entre jovens, os quais integram parte da população grandemente exposta a agentes infecciosos. A descoberta e iniciação sexual precoce, relacionada à prática de sexo de forma insegura, como múltiplas parcerias, relações sexuais sob influência de álcool ou drogas, uso inconsistente do preservativo, as fragilidades nas ações de educação em saúde, e a falta de diálogo aberto sobre o assunto, colaboram para que o grupo se torne uma das parcelas da população mais suscetíveis a contrair doenças, principalmente aquelas transmitidas pelo contato sexual. Atualmente, a maioria de novas infecções pelo HIV acometem jovens na faixa etária entre 15 a 24 anos. ${ }^{4-5}$

Com o ingresso na universidade, incide sobre os jovens a necessidade de buscar novas amizades e tentar adaptar-se à atual rotina de compromissos. Com as atividades antes não vivenciadas e com maior independência e liberdade, aparecem ambientes de distração e diversão para amenizar a tensão. Nesse seguimento, muitos universitários procuram em festas e eventos a descontração necessária para encarar esse turbilhão de acontecimentos, impulsionando diferentes formas de comportamento e hábitos de vida. ${ }^{6}$

Apesar das exposições vivenciadas, eles não se consideram vulneráveis e estigmatizam a pessoa que contrai uma IST como “marginal”, como se apenas os “outros” estivessem expostos. A população universitária da área da saúde, muitas vezes, não demonstra preocupação com relação às IST, fato que não se aplica, necessariamente, à falta de conhecimento, que é um dos riscos para o desenvolvimento das infecções. Ainda, significativa parte dos universitários desconhecem os principais sintomas, formas de transmissão e prevenção, principalmente, de 
infecções de grande ocorrência e de baixa abordagem em meios de comunicação. ${ }^{7-8}$

No que diz respeito ao conhecimento e aos aspectos comportamentais dos jovens, podese notar que as Instituições de Ensino Superior (IES) possuem papel essencial na educação e formação de seus acadêmicos. A universidade é responsável pela geração de futuros profissionais capacitados para executar ações educativas que reconheçam as verdadeiras necessidades, vontades e aspirações dos indivíduos susceptíveis à algum tipo de IST e, principalmente, compreender as vulnerabilidades os quais estão expostos. ${ }^{7}$

A prevenção é a estratégia fundamental para o controle da transmissão das IST. O uso de preservativos e a introdução de medidas e atividades educativas, por meio da constante informação, são aspectos que colaboram para a redução das taxas crescentes de infecções. Ressalta-se, ainda, as estratégias de prevenção combinadas como a testagem rápida, acesso ao tratamento logo após a confirmação do diagnóstico, as profilaxias para estes agravos e as imunizações disponíveis. Isso sem contar a importância de conhecer o perfil da educação sexual dos indivíduos, além da realidade destes jovens, de forma que se torne mais fácil a troca de informações e esclarecimentos a respeito do tema. Todos esses cuidados permitem um trabalho de melhores resultados com esta população e diminuem o ônus para o sistema de saúde e as complicações referentes à qualidade de vida da população jovem. ${ }^{9}$

A partir dessas considerações, salienta-se a relevância da temática, visto que a realidade tem mostrado que ainda são discretas as iniciativas no meio universitário para a disseminação do conhecimento entre seus discentes em relação às IST. Além dos jovens estarem numa faixa etária suscetível, eles serão futuros profissionais e, portanto, formadores de opinião na sociedade. Com isso, a problemática deste estudo envolve o nível de conhecimento dessa população quanto à temática e como se comportam em relação à prevenção das IST.

Assim, tem-se como questão de pesquisa: qual o conhecimento e comportamento de acadêmicos de enfermagem acerca das IST? E como objetivo do estudo: descrever o 
5 | Merenhque CC. Barreto CN, Cremonese L, Sehnem GD, Demori CC, Neves ET

conhecimento e comportamento de acadêmicos de enfermagem acerca das IST.

\section{Método}

Trata-se de uma pesquisa de abordagem qualitativa e caráter descritivo. A técnica utilizada para a produção das informações foi empregada para entendimento de um assunto com profundidade por intermédio de uma abordagem coletiva. O debate grupal possibilita aos participantes trocar, concordar ou discordar a respeito de determinado assunto. A partir das recomendações da técnica de grupo focal, havia um moderador grupal para estimular as discussões entre os participantes, bem como, para intervir quando necessário e um observador para registrar as percepções de cada sessão grupal. ${ }^{10}$

A população foi composta por 143 acadêmicos de enfermagem, dos quais oito preencheram o formulário de participação da pesquisa. Destes, sete atenderam aos critérios de inclusão, sendo que após o primeiro encontro houve desistência de um dos participantes devido a organização de sua agenda, totalizando seis participantes nos demais encontros. O cenário do estudo foi um Campus universitário de uma instituição privada do interior do Rio Grande do Sul, no qual as aulas ocorriam no turno da noite.

A seleção dos participantes ocorreu de forma aleatória, por meio de convite e interesse dos acadêmicos do curso em participar do estudo. Os critérios de inclusão compreenderam discentes do curso de enfermagem da referida instituição, a partir do terceiro semestre (período em que ocorre o início das disciplinas que abordam a temática em questão) e maiores de 18 anos. Como critério de exclusão, adotou-se: estudantes de graduação em enfermagem em afastamento ou que efetuaram trancamento do curso. A divulgação ocorreu por meio de mídias sociais (grupos do curso no WhatsApp e Facebook) e, posteriormente, pelo preenchimento de um formulário online de interesse de participação da pesquisa, que deveria ser preenchido com idade, semestre, telefone e e-mail, no qual a pesquisadora efetuou contato via e-mail para 
agendamento das sessões grupais.

As informações foram produzidas em novembro de 2019, sendo desenvolvidos três encontros grupais. Com o intuito de promover a discussão acerca do tema foco, elaborou-se guias temáticos para a construção das sessões grupais, de acordo com a finalidade da pesquisa. Essa ferramenta serviu como uma orientação, sistematizando questões e objetivos para cada encontro. Para incentivar a discussão entre os universitários, recorreu-se a aplicação de estratégias que fomentassem a participação ativa dos acadêmicos. O debate era encerrado a partir do critério de saturação de dados, que consiste na repetição das falas. ${ }^{11}$ Destaca-se que para execução dos grupos foram respeitados os preceitos éticos de pesquisa com seres humanos, assim como a assinatura do Termo de Consentimento Livre e Esclarecido pelos participantes. A seguir, estão descritos os guias temáticos utilizados na sessão grupal:

O $1^{\circ}$ encontro visava abordar sobre o que são as IST e se ser acadêmico em enfermagem influencia no comportamento de risco e prevenção. Foram utilizadas figuras relacionadas ao ambiente universitário, IST, gênero, prevenção e risco a fim de estimular as trocas entre os participantes.

O $2^{\mathrm{o}}$ encontro teve como objetivo discutir conceitos de juventude e risco; Gênero e IST; Comportamento de risco e/ou prevenção. A sessão foi iniciada com um vídeo disparador acerca do sexo lésbico. Também, foram trazidos pela pesquisadora mitos e verdades sobre prevenção e comportamento de risco.

O $3^{\text {º }}$ encontro foi destinado a representação de estratégias para fortalecer as ações de prevenção às IST. Nesse último, foram sintetizadas as produções dos encontros anteriores e, a partir de uma produção em papel pardo, foram discutidas no grupo estratégias para redução dos índices relacionados às infecções e práticas de cuidado para fortalecer ações de prevenção no contexto acadêmico.

Destaca-se que na execução dos grupos focais, foi pactuado que as informações discutidas 
seriam mantidas em sigilo pelo grupo e utilizadas apenas para fins acadêmicos. Também, foram sintetizadas coletivamente as ideias e discussões provocadas, em concordância com todas as partes e acompanhadas pelo moderador e observador ao longo das sessões. Os encontros ocorreram em sala específica no campus selecionado e cada sessão durou em torno de 1h30min.

As informações coletadas foram gravadas em smartphone, com a autorização dos participantes, e, em seguida, transcritos para análise e interpretação do pesquisador. A análise das informações foi fundamentada na análise de conteúdo operativa, à qual compreende as seguintes fases: pré-análise, exploração do material, tratamento e interpretação dos dados. ${ }^{11}$ Para fins do estudo, os acadêmicos de enfermagem serão identificados como AE e com numeração aleatória.

O estudo foi aprovado pelo Comitê de Ética em Pesquisa da instituição pesquisada, em 30 de outubro de 2019, sendo registrado sob o número de parecer 3.678 .235 e CAAE 23755119.2.0000.5349. Além disso, os preceitos da Resolução n 466/12 do Conselho Nacional de Saúde do Ministério da Saúde, que regem as pesquisas incluindo seres humanos, foram ininterruptas durante a totalidade do estudo.

\section{Resultados}

No que concerne aos participantes, um era do sexo masculino e seis do feminino. Havia um estudante do quinto semestre, dois do oitavo e os demais do décimo, com idades entre 21 e 38 anos. As informações foram organizadas em quatro categorias temáticas, sendo elas: vulnerabilidades relacionadas às IST vivenciadas por universitários; influência do conhecimento adquirido na graduação nas práticas sexuais e comportamentos de risco; diversidade sexual e prevenção das IST; e estratégias para prevenção de IST no ambiente acadêmico. 


\section{Vulnerabilidades relacionadas às IST vivenciadas por universitários}

Ao relacionar as IST e o público universitário, a partir das falas dos acadêmicos de enfermagem, houve apontamentos a respeito das vulnerabilidades e susceptibilidades. O uso de substâncias psicoativas é salientado, também, pelos participantes:

Por se tratar de jovens [...] parece a sensação de que comigo nada vai acontecer. (AE2)

Eu acho que pelas suscetibilidades dessa pessoa frente a uma situação que ela pode não controlar bem ou não pensar muito bem sobre o que ela está fazendo, pensando em questão de juventude [...]. (AE5)

Questão de uso de drogas, a gente tem a questão de perder a noção de senso [...] não ter mais a percepção do mundo ao redor [...] na questão do álcool também, a juventude não tende a controlar o álcool que ingere. (AE3)

Os acadêmicos relataram que, ao refletir acerca das IST, na maioria das vezes, acreditavam ser uma situação que com eles não aconteceria, como se estivessem protegidos dos riscos ao se exporem. Ainda, destacaram a juventude como um processo de amadurecimento, apresentando algumas fragilidades nas suas decisões. Também, outro fator relevante é o uso de álcool e outras drogas, de maneira incontrolada, que pode acarretar maior risco de IST.

O uso do preservativo foi associado a um fator de proteção, porém ainda há receio do não uso em determinadas ocasiões. Ou seja, os estudantes têm a percepção de risco, mas acabam não adotando condutas sexuais seguras em alguns momentos:

Eu mesmo me protegendo me sinto vulnerável. [...] minha mãe sempre me orientou a usar preservativo para evitar IST, não para prevenir filhos. E aí foi um hábito meu, desde jovem eu sempre utilizei, não lembro de alguma vez não ter utilizado, e mesmo assim sou medroso. (AE4)

Eu consigo ter um comportamento tranquilo, mas já fiz sexo sem camisinha com uma pessoa que eu não conhecia, há muito tempo, não vou dizer que não. Eu fico com medo, às vezes. (AE6) 
9 | Merenhque CC. Barreto CN, Cremonese L, Sehnem GD, Demori CC, Neves ET

Eu acho que depois que virou um só [casal], tudo ficou mais fácil. A gente cuida, mas existia um risco e existe sempre o medo por trás. Para mim sempre existiu pelo menos. (AE5)

Os participantes relataram o sentimento de "medo" em determinadas situações e, a maioria, o uso do preservativo para prevenção de IST. Porém, mesmo tendo consciência dos riscos, já ocorreram situações de exposição sexual sem o uso do método de barreira. Outro ponto ressaltado foi o não uso do preservativo em relacionamentos sérios e duradouros, justificado pela confiança adquirida no parceiro. Entretanto, esse aspecto não os deixava tranquilos.

Além disso, existe a chance da ocorrência de relações extraconjugais sem o uso de camisinha. Dessa forma, a não compreensão da própria vulnerabilidade, associado a fidelidade do casal, pode induzir ao comportamento de risco:

[...] muitas vezes, tu tens um relacionamento estável com uma pessoa e tu acaba mantendo um relacionamento extraconjugal e [...] as pessoas acabam deixando de usar preservativo porque estão tendo um relacionamento mais duradouro, só que não deixa de ser um risco porque tu não sabes se aquela pessoa que tu estás te relacionando, possui um relacionamento só contigo. (AE1)

A grama do vizinho é mais verde e a gente dá uma pastada de vez em quando. Se tu tens uma relação extraconjugal, tu acabas se colocando em risco. (AE3)

Quanto ao meio acadêmico e a ocorrência de uma vida sexual mais ativa, os estudantes destacaram a influência do ambiente nas relações. A diversidade cultural, aliada a ânsia de viver intensamente, os induzem a assumir diferentes comportamentos:

[...] com certeza influencia muito [...] porque são jovens muitas vezes da tua idade, que geralmente nessa faixa etária não se assumiram ainda e querem se descobrir. Então na faculdade se descobre e acaba ocasionando experiências novas, com pessoas que você não conhecia antes, com pessoas que não são da sua cidade e vêm para a faculdade. (AE4) 
[...] a faculdade acaba sendo tua desculpa [...] E aí é no calor da hora que tu tens a oportunidade e tu abraça a oportunidade. E muitas vezes tu não estás nem pensando, tu não sais de casa com uma camisinha na bolsa, não sai de casa esperando. (AE1)

Além de aumentar o número de contatos, a faculdade é citada como um refúgio e um espaço de novas descobertas. O ingresso nesse ambiente e grupo social, associado ao desenvolvimento da independência nessa fase da vida, faz com que os discentes se coloquem em situações de risco e vulnerabilidade. Além da exposição a novas experiências, estão expostos ainda a novas influências e acabam mostrando-se abertos a elas.

\section{Influência do conhecimento adquirido na graduação nas práticas sexuais e comportamentos de risco}

Ao serem indagados sobre o comportamento sexual após o ingresso na graduação, mais especificamente no curso de Enfermagem, os participantes demonstram haver influência em suas falas. Os novos conhecimentos adquiridos no processo de formação são capazes de subsidiar novas práticas e pensamentos:

Aqui a gente ouve muito mais sobre isso e também presencia casos. (AE7)

O conhecimento gera uma conscientização. De início pode ser que talvez não, mas depois de tanto tu ver, tanto tu saber de situações sobre, vai modificando devagar o pensamento. (AE5)

Percebe-se, também, que os estágios curriculares e as aulas práticas na atenção primária foram grandes influenciadores no que diz respeito às condutas sexuais. O envolvimento dos estudantes com a comunidade proporciona reflexões sobre estigmas:

Antes do estágio na atenção primária sim [praticava sexo sem preservativo]. Depois, não! De jeito maneira. No estágio a gente vê muita coisa, e como eu disse, não está estampado, a pessoa não vai chegar e dizer 
11 Merenhque CC. Barreto CN, Cremonese L, Sehnem GD, Demori CC, Neves ET

“Oi, tudo bem? Quer sair comigo? Eu tenho Sifilis". A pessoa não vai te dizer. [...] E aí daqui a pouco a pessoa está infectada e eu não sei [...] aí tu começas a ver que não é só a pessoa que mora lá nas margens da sociedade, não é só a pessoa que faz ponto na esquina. (AE1)

Anterior ao conhecimento universitário adquirido na academia, os jovens relataram praticar sexo sem proteção, mas após aulas práticas e estágios conscientizaram-se em relação ao assunto. Os acadêmicos, como multiplicadores de prevenção, foram estimulados, também, a assunção de uma postura mais comprometida no que tange suas ações.

\section{Diversidade sexual e a prevenção das IST}

A partir de questionamentos ligados à saúde e a prevenção de IST na população lésbica, gay, bissexual, travesti e intersexual (LGBTI+), sendo estimulada a discussão por meio de vídeo sobre o sexo lésbico, os estudantes deveriam discorrer, caso soubessem, a respeito de como é realizada a prevenção nesse tipo de relação. Observa-se que ainda há desinformação acerca da temática:

[...] não é um preservativo instituído, feito em fábrica, "né”, mas seria a aplicação de um filme de PVC, um filme plástico sobre a vulva, o que dá uma certa segurança porque não vai ter o contato de secreção e aí sobre o filme plástico poderia ser feito o sexo entre mulheres, que seria um jeito que se encontrou de conseguir ser preventivo. (AE5)

Não tenho conhecimento sobre. (AE1)

Quanto ao atendimento a essa população, os participantes revelaram algumas falhas que ocorrem durante esse processo. Deve-se buscar desconstruir os estigmas do preconceito que, muitas vezes, acabam promovendo a exclusão social:

Tem uma barreira bem grande a ser passada por aí, porque a gente tem o conhecimento adquirido, porém existe aquele esquema do preconceito, [...] existe uma barreira de comunicação também, entre a população LGBTI+e os profissionais de saúde. [...], então é bem difícil a comunicação para conseguir expor, falar sobre IST, conseguir falar sobre métodos 
Conhecimento e comportamento de acadêmicos de enfermagem acerca da... | 12

preventivos, questão de acompanhamento periódico [...] (AE3)

Tem que ter uma empatia para atender essa população, tu tens que saber acolher ela e não fazer um pré-julgamento de quando ela vai chegar lá. (AE6)

[...] a menina foi fazer teste rápido [...] aí a gente começou a orientar ela, aí começou a falar "teu parceiro, teu parceiro", até que ela falou não, que ela não tinha parceiro, ela tinha era uma companheira. Aí a gente não sabe o que dizer, porque nós não nos preparamos para isso, é uma falha. Tu não estás preparado. (AE1)

No tocante à formação, os universitários revelaram ser um tema pouco abordado na academia. Isso contribui para a ocorrência de práticas discriminatórias, o que faz com que a instituição acabe se tornando um lugar não tão receptivo para aqueles alunos que possuem sexualidade e gênero não normativos:

Eu acho que se trabalha muito pouco. E eu espero que a tendência seja sempre melhorar, abordar mais [...]. E a gente sabe por que ouve colegas comentando "Ah, que coisa chata, eu não aguento mais ouvir professor falando sobre isso". A população LGBT, tu não tens certeza se vai, quando é que vai procurar o serviço. Vai fazer teste rápido? De quanto em quanto tempo?[...] então, eu acho que cada vez mais a gente tem que trabalhar e a faculdade ainda perca um pouco, porque ainda tem pessoas que reclamam. (AE5)

Eu já presenciei de colegas de graduação [quando foram formar grupos] de levantar e dizer "Eu não vou ficar no mesmo grupo que esses viados". Ele levantou, pegou sua cadeira, suas coisas e saiu. Aí pensa, esse vai ser o profissional que vai atender amanhã?(AE1)

A não existência de disciplinas e espaços para discussão a respeito do assunto acabam gerando uma reprodução de discriminação por parte dos colegas. Deve-se buscar uma educação que não reproduza preconceitos de sexualidade e gênero, mas para isso, uma mudança nos currículos universitários também deve ocorrer. 
13 Merenhque CC. Barreto CN, Cremonese L, Sehnem GD, Demori CC, Neves ET

\section{Estratégias para prevenção de IST no ambiente acadêmico}

Os participantes apresentaram estratégias para fortalecer as ações de prevenção de IST em nível acadêmico. O debate sobre o tema em uma ação conjunta com a participação dos acadêmicos e discentes pode orientar a conduta e tomada de decisões dos envolvidos:

Capacitar alguns acadêmicos para desenvolver uma ação com os demais universitários. [...] um grupo de apoio para toda a universidade. [...] não sei se caberia oferecer teste rápido... E, também, material educativo. (AE2)

Eu pensei em pegar assim, na hora da entrada [da universidade], que é um horário de pico, segurar o pessoal 5 minutinhos: "Olha, gente [...] hoje a gente tem ' $x$ ' casos de tal IST, ' $X$ ' casos de HIV, ' $X$ ' casos de Sifilis" [...] Mostrar que a gente está exposto e o que a gente está fazendo para mudar isso [...]. A gente está ajudando a disseminar mais ou o quê? [...] oferecer [testagem rápida] em diversos horários do dia. Ter um horário bem delimitado, que não pegasse só no horário da noite, porque tem gente que fica com vergonha. (AE5)

Fortalecimento de ações nas escolas, acho que mais em séries iniciais. (AE7)

Abordar a temática com universitários de outros cursos é de grande importância, visto que, estudantes que não são da área da saúde, raramente, possuem em sua grade curricular disciplinas que abordem as IST. A falta de orientações e o desconhecimento dos riscos contribui para a vulnerabilidade destes indivíduos.

\section{Discussão}

Características comuns da juventude, como a imaturidade e a inexperiência, por exemplo, podem ocasionar consequências prejudiciais à saúde e à vida desses indivíduos, os quais, muitas vezes, não são capazes de identificar os riscos a que estão expostos e acabam negligenciando a importância de atitudes protetivas. ${ }^{4}$ A partir dos depoimentos, pode-se observar que os jovens, independentemente do gênero, são uma parcela vulnerável em todas as sociedades do mundo 
globalizado. Situações como o consumo abusivo de álcool e drogas são relevantes para oferta de cuidados à saúde, uma vez que determinam algumas das vulnerabilidades mais comuns nessa fase da vida. ${ }^{12}$

A população jovem, em especial os universitários brasileiros, envolve-se facilmente com o consumo de bebidas alcoólicas e outras drogas ilícitas, seja pelo acesso fácil, baixo custo ou até mesmo pela pressão social por parte dos amigos e/ou colegas. ${ }^{13}$ Ao fazer uso dessas substâncias, grande parte destas pessoas acabam tendo uma percepção diminuída quanto ao comportamento sexual e assumem uma prática de risco diante das IST.

À medida que as relações se tornam mais estáveis, alguns casais acabam abandonando o uso da camisinha, a qual, atualmente, é o único método que protege contra a maioria das IST, mesmo não apresentando uma eficácia de 100\%. ${ }^{14}$ Esse relaxamento quanto ao uso acaba deixando os indivíduos mais suscetíveis a adquirirem alguma IST, uma vez que existe a possibilidade de o indivíduo estar infectado e não saber, o que pode ocasionar na transmissão para o cônjuge.

O fato de estar em um relacionamento estável faz os estudantes pensarem que não estão vulneráveis a adquirirem algum tipo de IST, razão pela qual não adotam medidas de prevenção. Outro ponto abordado, refere-se aos relacionamentos extraconjugais que, além de trazerem riscos para quem mantém esse tipo de relação, também resultam em danos para os parceiros sexuais dos envolvidos.

Dessa forma, apesar da relação traição/contágio estar presente em diversos momentos, muitos casais não identificam o risco pessoal para as IST, fazendo com que o uso do preservativo continue sendo deixado de lado nas relações estáveis, pois se sentem protegidos durante o relacionamento. Porém, identifica-se que em relacionamentos extraconjugais, o preservativo, em alguns momentos, também não é utilizado. ${ }^{15}$

Corroborando os achados, é comum que, com o ingresso no ensino superior, os jovens se 
15 | Merenhque CC. Barreto CN, Cremonese L, Sehnem GD, Demori CC, Neves ET

afastem de suas famílias, indo residir em outras cidades. As novas obrigações trazem independência e expectativas ao que diz respeito às decisões do dia a dia. Dessa forma, enfrentam novos desafios e esbarram em situações que vão moldando a sua personalidade. Essas novas construções levam os jovens a agir com mais autonomia, além de ter de criar e respeitar seus próprios limites, o que acaba ocasionando, muitas vezes, dificuldades, estresse e exposição dos universitários a práticas de risco para a saúde. ${ }^{6}$

Os estudantes revelaram que ser acadêmico de enfermagem influencia nas práticas sexuais. O conhecimento obtido ao decorrer do curso interfere no autocuidado, e as situações vivenciadas na academia são responsáveis por transformar tal visão, fazendo com que se tenha uma maior consciência e, consequentemente, comportamentos de prevenção. Dessa forma, os estudantes puderam notar que a pessoa infectada com alguma IST não pode ser estigmatizada como pertencente a um determinado grupo e sim, que os comportamentos de risco estão presentes em todos os indivíduos da sociedade, independente de sexo, religião, profissão, etc., desmistificando a falsa sensação de segurança pautada no discurso de que apenas "determinadas populações” pudessem ser contaminadas.

Os profissionais da saúde, em especial os enfermeiros, necessitam se apropriar dos conhecimentos essenciais para a realização de cuidados e redução de estigmas referentes as pessoas com IST, o que pode ser fomentado durante a formação de graduação e durante toda a vida profissional, em processos de educação permanente. Para atender tal paciente de maneira efetiva, é indispensável que o profissional tenha compreensão específica a respeito do mesmo e das necessidades demandadas no momento. ${ }^{16}$ Quanto à Atenção Primária à Saúde (APS), a Unidade Básica de Saúde (UBS) é o local principal para o cuidado de usuários com IST/AIDS, onde o profissional de Enfermagem é responsável pela prevenção e promoção da saúde, contribuindo com a melhora da qualidade de vida a todo o público de forma igualitária, devendo deixar de lado suas próprias crenças e preconceitos. 
Nos depoimentos, percebe-se que, apesar de conhecerem um dos principais métodos de prevenção, ainda há falta de informação acerca do tema. A promoção de debates nessa direção, a vivência em cenários reais da prática, durante estágios acadêmicos, a fim de promover o pensamento claro e crítico, impactam claramente na formação acadêmica. Além do meio acadêmico, a APS é sinalizada, também, como área especial para abordar e disseminar orientações, em que o profissional de saúde deve estar atento para acolher e fornecer informações sobre o uso de preservativo.

O sexo oral sem proteção manifesta ameaça para o desenvolvimento de IST, como tricomoníase, vaginoses, HPV e herpes genital. No caso de mulheres que fazem sexo mulheres não é diferente, pois há a troca de secreções vaginais no decorrer da masturbação revezada, do tribadismo (vagina com vagina) e do uso e compartilhamento de brinquedos eróticos. ${ }^{17}$ Ainda há a associação de IST ao envolvimento sexual com homens e isso faz com que a relação exclusiva entre mulheres possa ser vista como um fator de proteção e que não requer cuidados específicos.

Atualmente, não existe na rede de saúde proteção específica para o sexo oral em mulheres, porém, o uso de películas para essa prática, que podem ser preservativos ou películas como plástico protetor ou luvas, correspondem a técnicas eficientes para a prevenção. ${ }^{18}$ Diante disso, verifica-se a necessidade da elaboração de materiais mais apropriados às práticas sexuais dessa população, produzidos com base no debate em relação as particularidades da sexualidade para que sejam efetivos e viáveis, tanto na prevenção, quanto em adequar o seu uso a realidade.

Nota-se que o atendimento à população LGBTI+ ainda é um desafio a ser superado. Há uma fragilidade significativa na assistência, por vezes discriminatória e heteronormativa, praticada pelos profissionais. Verifica-se entre os estudantes o despreparo para atender esse grupo, o que contribui para a dificuldade de acesso, aumentando a vulnerabilidade à qual os sujeitos estão expostos. À vista disso, é necessário que se tenha uma reformulação nos currículos de enfermagem a fim de que, durante a graduação, o aluno seja preparado para 
17 | Merenhque CC. Barreto CN, Cremonese L, Sehnem GD, Demori CC, Neves ET

realizar os cuidados necessários, de maneira humana e igualitária, a esta população.

O público em questão apresenta resistência à procura dos serviços de saúde, o que, em síntese, revela, além do cenário discriminatório presente, ordenado em função de uma heterossexualidade pressuposta, a ausência de qualificação e o preconceito dos profissionais de saúde para acolher a procura. Em razão de não se encontrar acolhidos e não identificar que as próprias demandas são concretizadas, acabam afastando-se dos serviços de saúde. ${ }^{19}$

Os participantes relataram haver dificuldade e preconceito entre os próprios colegas para lidar com essa população, fator responsável por impedir o acesso do grupo LGBTI+ à saúde. Salienta-se a importância de se trabalhar cada vez mais esse assunto, de forma que a universidade e o curso de enfermagem sejam um espaço aberto e inclusivo a todos e não mais uma maneira de exclusão e preconceito, pois além de existirem alunos pertencentes à comunidade LGBTI+, ali estão, também, futuros profissionais que prestarão atendimento a essa população.

Nesse seguimento, a reestruturação dos serviços de saúde para a integralização da população LGBTI+ depende das mudanças no modo de pensar e agir dos profissionais e, também, futuros profissionais de saúde. As questões culturais provenientes do padrão cis-heteronormativo induzem a assistência prestada pelos trabalhadores da área, o que os leva a atender todos os clientes como se fossem heterossexuais, gerando situações de discriminação e preconceito. ${ }^{20}$

O fortalecimento de estratégias dentro da universidade é uma iniciativa que possibilita ao estudante conversar sobre sexualidade e receber dicas, além de proporcionar um maior número de informações a respeito das IST. Fornece novos espaços e ferramentas para que a população acadêmica possa se prevenir é uma excelente maneira de promover a educação sexual e a prevenção.

A importância da escola, bem como da universidade, tem sido salientada como um ambiente de socialização, onde a comunicação entre amigos e educadores faz com que esses locais sejam vistos como lugares para tratar de questões referentes às IST, bem como práticas de promoção da saúde. ${ }^{21-22}$ As ações educativas em saúde possuem um efeito positivo à medida que 
os indivíduos começam a se cuidar. Por receberem um conhecimento anterior a suas decisões, muitas vezes, transformam-se em sujeitos conscientes de suas práticas, reduzem as condutas de risco e assumem práticas sexuais seguras, protegendo-se contra as IST. ${ }^{23}$

Como limitação do estudo, aponta-se que os dados são de apenas uma instituição e de um curso específico. Assim, sugere-se a ampliação do estudo com outros acadêmicos e outras instituições de ensino do estado e país.

\section{Conclusão}

Os acadêmicos de enfermagem da instituição pesquisada possuem conhecimento em relação às IST, porém, sentem-se vulneráveis e expostos a situações de risco. Eles relataram comportamentos de risco, tais como o não uso do preservativo numa relação estável e duradora.

$\mathrm{O}$ ingresso no curso de Enfermagem proporcionou aos acadêmicos maior conhecimento em relação à temática e os fez repensar o próprio comportamento de risco e as práticas de prevenção. Porém, esse conhecimento não é fator determinante para o uso de preservativo em todas as relações sexuais.

Destaca-se a necessidade de implantar ações de educação em saúde no meio acadêmico para todos os cursos, abordando temáticas relacionadas às IST, população LGBTI+, estigmas, preconceito e discriminação. Além do autocuidado, o conhecimento também é fator indispensável no cuidado ao próximo, visto que o profissional de enfermagem atuará diretamente com pessoas que vivem com ou em risco de contrair alguma IST.

Corroborando as estratégias demonstradas pelos estudantes durante a pesquisa, é aconselhável que as instituições de ensino, especialmente, as universidades e os cursos de enfermagem, elaborem práticas educativas com os universitários por meio de projetos de extensão e inclusão de disciplinas relacionadas à sexualidade. Dessa forma, além de discutir e promover a reflexão a respeito dos comportamentos e vulnerabilidades a que estão expostos, 
19 | Merenhque CC. Barreto CN, Cremonese L, Sehnem GD, Demori CC, Neves ET

contribui para o esclarecimento e redução de riscos dessa população fortemente vulnerável.

\section{Referências}

1. Ministério da Saúde (BR), Secretaria de Vigilância em Saúde. Departamento de DST, Aids e Hepatites Virais. Protocolo clínico e diretrizes terapêuticas para a atenção integral às pessoas com Infecções Sexualmente Transmissíveis. Brasília (DF): Ministério da Saúde; 2020.

2. Hughes G, Field N. The epidemiology of sexually transmitted infections in the UK: impact of behavior, services and interventions. Future Microbiol. 2015;10(1):35-51. doi: 10.2217/fmb.14.110

3. World Health Organization (WHO). Sexually transmitted infections (STIs): the importance of a renewed commitment to STI prevention and control in achieving global sexual and reproductive health. Geneva (CH): WHO; 2015.

4. Ministério da Saúde (BR), Secretaria de Vigilância em Saúde. Departamento de DST, Aids e Hepatites Virais. Boletim Epidemiológico HIV/Aids. Brasília (DF): Ministério da Saúde; 2016.

5. Dantas KTB, Spindola T, Teixeira SVB, Lemos ACM, Ferreira LEM. Young academics and the knowledge about sexual transmitted diseases - contribution to care in nursing. Rev Pesq Cuid Fundam. 2015;7(3):3020-36. doi: 10.9789/2175-5361.2015.v7i3.3020-3036

6. Borges MR, Silveira RE, Santos AS, Gazi U. Comportamento sexual de ingressantes universitários. Rev Pesq Cuid Fundam. 2015;7(2):2505-15. doi: 10.9789/2175-5361.2015.v7i2.2505-2515

7. Fonte VRF, Spindola T, Lemos A, Francico MTR, Oliveira CSR. Conhecimento e percepção de risco em relação às infecções sexualmente transmissíveis entre jovens universitários. Cogitare Enferm. 2018;23(3):e55903. doi: 10.5380/ce.v23i3.55903

8. Castro EL, Caldas TA, Morcillo AM, Pereira EMA, Velho PENF. O conhecimento e o ensino sobre doenças sexualmente transmissíveis entre universitários. Ciênc Saúde Colet. 2016;21(6):1975-84. doi: 10.1590/1413-81232015216.00492015

9. Monteiro SS, Brandão E, Vargas E, Mora C, Soares P, Daltro E. Discursos sobre sexualmente em um centro de testagem e aconselhamento (CTA): diálogos possíveis entre profissionais e usuários. Ciênc Saúde Colet. 2014;19(1):137-46. doi: 10.1590/1413-81232014191.1906

10. Sehnem GD, Alves CN, Wilhelm LA, Ressel LB. Utilização do grupo focal como técnica de coleta de dados em pesquisas: relato de experiência. Ciênc Cuid Saúde. 2015;14(2):1194-200. doi: 10.4025/cienccuidsaude.v14i2.21960

11. Minayo MCS. O desafio do conhecimento: pesquisa qualitativa em saúde. 14ํa ed. São Paulo: Hucitec; 2014. 
12. Ministério da Saúde (BR), Comissão Nacional de Incorporação de Tecnologias no SUS. Protocolo de Diretrizes Terapêuticas, Infecções Sexualmente Transmissíveis. Relatório de Recomendação [Internet] Brasília (DF): Ministério da Saúde; 2015 [acesso em 2020 abr 19]. Disponível em: http://conitec.gov.br/images/Consultas/Relatorios/2015/Relatorio_PCDT_IST_CP.pdf

13. Mola R, Pitangui ACR, Barbosa SAM, Almeida LS, Sousa MRM, Pio WPL, et al. Condom and alcohol consumption in adolescents and youth. Einstein. 2016;14(2):143-51. doi: 10.1590/S1679-45082016AO3677

14. Delatorre MZ, Dias ACG. Conhecimentos e práticas sobre métodos contraceptivos em estudantes universitários. Rev SPAGESP [Internet]. 2015 [acesso 2020 abr 25];16(1):60-73. Disponível em: http://pepsic.bvsalud.org/pdf/rspagesp/v16n1/v16n1a06.pdf

15. Horan SM, Cafferty LA. Condom communication: reports of sexually active young adults' recent messages with new partners. J Health Commun. 2017;22(9):763-71. doi: 10.1080/10810730.2017.1355420

16. Cordeiro JKR, Santos MM, Sales LKO, Morais IF, Dutra GRS. School teenagers about STD/AIDS: when knowledge does not follow safe practices. Rev Enferm UFPE On Line [Internet]. 2017 [cited 2020 Apr 25];11(suppl 7):2888-96. Available https://periodicos.ufpe.br/revistas/revistaenfermagem/article/view/9014/19197

17. Rufino AC, Madeiro A, Trinidad A, Santos R, Freitas I. Sexual practices and health care of women who have sex with women: 2013-2014. Epidemiol Serv Saúde. 2018;27(4):e2017499. doi: 10.5123/s167949742018000400005

18. Knight DA, Jarrett D. Preventive health care for women who have sex with women. Am Fam Physician [Internet]. 2017 [cited 2020 Apr 20];95(5):314-21. Available from: https://www.aafp.org/afp/2017/0301/p314.pdf

19. Fernandes B. Educação popular em saúde: um diálogo da sociedade civil com os postos de saúde em Goiânia. Tempus (Brasília). 2017;11(1):29-39. doi: 10.18569/tempus.v11i1.2358

20. Araujo LC, Penna LHG, Carinhanha JI, Costa CMA. O cuidado às mulheres lésbicas no campo da saúde sexual e reprodutiva. Rev Enferm UERJ. 2019;27:e34262. doi: 10.12957/reuerj.2019.34262

21. Fonte VRF, Spindola T, Francisco MTR, Sodré CP, André NLNO, Pinheiro CDP. Jovens universitários e o conhecimento acerca das infecções sexualmente transmissíveis. Esc Anna Nery. 2018;22(2):e20170318. doi: 10.1590/2177-9465-ean-2017-0318

22. Abreu LDP, Mendonça GMM, Araújo AF, Torres RAM, Silva MRF, Fialho AVM. Cuidado de enfermagem na relação saber/poder e sexualidade junto a juventude escolar via web rádio [Internet]. Rev Enferm UFSM. 2019 [cited 2020 Apr 19];9(e54):1-21. Available from: https://periodicos.ufsm.br/reufsm/article/view/33663

23. Grangeiro A, Kuchenbecker R, Veras MA. Novos métodos preventivos para o HIV: reconhecendo as 
21 | Merenhque CC. Barreto CN, Cremonese L, Sehnem GD, Demori CC, Neves ET

fronteiras entre a autonomia dos indivíduos e as políticas públicas. Rev Bras Epidemiol. 2015;18(Suppl 1):1-4. doi: 10.1590/1809-4503201500050001

Editor Científico Chefe: Cristiane Cardoso de Paula Editor Associado: Carine Vendruscolo

\section{Autor correspondente}

Camila Nunes Barreto

E-mail: camilabarreto_6@msn.com

Endereço: Martinho Lutero, 301 - Bairro Universitário

CEP: 96501595

\section{Contribuições de autoria}

\section{1 - Caroline Clemente Merenhque}

Concepção ou desenho do estudo/pesquisa, análise e/ou interpretação dos dados

\section{2 - Camila Nunes Barreto}

Concepção ou desenho do estudo/pesquisa, análise e/ou interpretação dos dados e revisão final com participação crítica e intelectual no manuscrito

\section{3 - Luiza Cremonese}

Análise e/ou interpretação dos dados, revisão final com participação crítica e intelectual no manuscrito

\section{4 - Graciela Dutra Sehnem}

Análise e/ou interpretação dos dados, revisão final com participação crítica e intelectual no manuscrito

\section{5 - Carolina Carbonell Demori}

Análise e/ou interpretação dos dados, revisão final com participação crítica e intelectual no manuscrito

\section{6 - Eliane Tatsch Neves}

Análise e/ou interpretação dos dados, revisão final com participação crítica e intelectual no manuscrito

\section{Como citar este artigo}

Merenhque CC. Barreto CN, Cremonese L, Sehnem GD, Demori CC, Neves ET. Conhecimento e comportamento de acadêmicos de enfermagem acerca da prevenção de infecções sexualmente transmissíveis. Rev. Enferm. UFSM. 2021 [Acesso em: Ano Mês Dia];vol.11 e4: 1-21. DOI: https://doi.org/10.5902/2179769243700 